\title{
ASO Author Reflections: Registry-Based Analysis of Radiation- Associated Angiosarcoma of the Breast Provides Unbiased Insights into this Disease
}

\author{
Samuli H. Salminen ${ }^{1,2}$ (1) , and Carl P. Blomqvist ${ }^{1,2}$ \\ ${ }^{1}$ Comprehensive Cancer Center, Helsinki University Hospital (HUH), Helsinki, Finland; ${ }^{2}$ University of Helsinki, Helsinki, \\ Finland
}

\section{PAST}

Radiation-associated angiosarcoma of the breast (RAASB) is increasingly diagnosed in breast cancer survivors. ${ }^{1}$ Previous research has highlighted the importance of radical surgery in the management of this disease. ${ }^{2}$ Unfortunately, most published research was performed in single centers, possibly hampering the interpretation of results. A recent registry-based analysis from The Netherlands reported a 5 -year overall survival rate of $40.5 \%{ }^{3}$

\section{PRESENT}

We performed a comprehensive analysis of RAASB patients identified from the database of the Finnish Cancer Registry over 25 years. ${ }^{4}$ Thus, our study provides a unique perspective of RAASB treatment and prognosis in a nationwide population with complete follow-up of all patients. We discovered that most RAASB patients are eligible for radical surgery, and therefore possibly curative treatment, emphasizing the importance of awareness of this

\footnotetext{
ASO Author Reflections is a brief invited commentary on the article "Treatment and prognosis of radiation-associated breast angiosarcoma in a nationwide population”, Ann Surg Oncol. 2019. https://doi.org/10.1245/s10434-019-08085-1.
}

(C) The Author(s) 2019

First Received: 19 November 2019; Published Online: 12 December 2019

S. H. Salminen

e-mail: samuli.h.salminen@helsinki.fi disease in the rapidly growing population of breast cancer survivors. Forty-five percent of patients later had a local recurrence, and planned lateral surgical margin was associated with improved survival, therefore underlining the impact of radical surgery. Furthermore, locally recurring disease has a tendency to progress into a metastatic disease, further impairing prognosis.

\section{FUTURE}

The evidence from this and previous studies suggests that the primary treatment of a localized RAASB is radical surgery. ${ }^{2-4}$ However, our study did not bring further clarity into what surgical margins are needed for local control, due to the retrospective nature of this rare disease and the lack of comprehensive information for all patients.

Regrettably, a number of RAASB patients later progress into metastatic disease. ${ }^{4}$ Due to the rarity of RAASB, few patients are included in prospective trials of medical treatment. Future work could build on the growing knowledge on the molecular biology basis of RAASB to perform prospective studies in the metastatic setting.

ACKNOWLEDGEMENTS Open access funding provided by University of Helsinki including Helsinki University Central Hospital.

DISCLOSURES Samuli H. Salminen and Carl. P. Blomqvist report no conflicts of interest.

OPEN ACCESS This article is licensed under a Creative Commons Attribution 4.0 International License, which permits use, sharing, adaptation, distribution and reproduction in any medium or format, as long as you give appropriate credit to the original author(s) and the source, provide a link to the Creative Commons licence, and indicate if changes were made. The images or other third party material in this article are included in the article's Creative Commons licence, unless indicated otherwise in a credit line to the material. If material is not 
included in the article's Creative Commons licence and your intended use is not permitted by statutory regulation or exceeds the permitted use, you will need to obtain permission directly from the copyright holder. To view a copy of this licence, visit http://creativecommons. org/licenses/by/4.0/.

\section{REFERENCES}

1. Salminen SH, Sampo MM, Bohling TO, Tuomikoski L, Tarkkanen M, Blomqvist CP. Radiation-associated sarcoma after breast cancer in a nationwide population: Increasing risk of angiosarcoma. Cancer Med. Sep 2018;7(9):4825-4835.

2. Morgan EA, Kozono DE, Wang Q, et al. Cutaneous radiationassociated angiosarcoma of the breast: poor prognosis in a rare secondary malignancy. Ann Surg Oncol. Nov 2012;19(12):3801-3808.

3. Rombouts AJM, Huising J, Hugen $\mathrm{N}$, et al. Assessment of Radiotherapy-Associated Angiosarcoma After Breast Cancer Treatment in a Dutch Population-Based Study. JAMA Oncol. Jan 242019.

4. Salminen HS, Wiklund T, Mika MS, et al. Treatment and prognosis of radiation-associated breast angiosarcoma in a nationwide population. Ann Surg Oncol. 2019. https://doi.org/10.1245/ s10434-019-08085-1.

Publisher's Note Springer Nature remains neutral with regard to jurisdictional claims in published maps and institutional affiliations. 